\title{
Knowledge Practice and Outcome of Quality Nursing Care Among Nurses in University of Calabar Teaching Hospital (UCTH)
}

\author{
Oyira, Emilia James ${ }^{1}$, Ella, R. E. ${ }^{1}$ \\ ${ }^{1}$ Department of Nursing Science, University of Calabar, Calabar \\ Correspondence: Oyira, Emilia James, Department of Nursing Science, University of Calabar, Calabar.
}

Received: March 7, 2016 Accepted: March 22, $2016 \quad$ Online Published: October 17, 2016

doi:10.11114/jets.v4i11.1926 URL: http://dx.doi.org/10.11114/jets.v4i11.1926

\begin{abstract}
Objectives: The main purpose of this study was to determine knowledge practice and outcome of quality nursing care among nurses in University of Calabar Teaching Hospital (UCTH). Three research questions and one hypothesis were formulated to guide this study. Literature related to the variables under study was reviewed according to the research questions and hypothesis formulated to guide the study. Survey research design was adopted for the study. Methods: The design involves the collection of data to accurately and objectively describe existing phenomena, and to make inferences about the population. A total sample of one hundred and forty (140) respondents was randomly selected for the study. The selection was done through the simple random sampling technique. This was to give each and every members of the population equal and independent opportunity of being selected for the study. The main instrument used for the collection of data, was the questionnaire. It was administered personally by the researchers with the help of two research assistants. To answer the research questions and test the hypotheses, frequencies, percentages, and contingency chi square analysis were considered the most appropriate statistical techniques because of the nature of the variables involved in the research questions and the formulated hypothesis directing the study. The hypothesis was subjected to testing at .05 level of significance with critical values and degree of freedom and the following results were obtained; Nurses at the University of Calabar teaching hospital have knowledge associated with the quality of nursing care rendered to patients at the hospital, Nurses at the University of Calabar teaching hospital Practiced quality nursing care. Nurses at the University of Calabar teaching hospital Rendered Quality nursing care which was reflected in the positive responses by patients in the hospital. There was a significant influence of knowledge on the practice of quality nursing care among nurses in University of Calabar Teaching Hospital. Conclusion: it was concluded among others that the hospital management should always remind nurses of their obligations to patients through continuing education this will help nurses to improve on quality nursing care to patients.
\end{abstract}

Keywords: knowledge, practice, outcome of quality nursing care, nurses, patients

\section{Introduction}

\subsection{Background to the Study}

Nursing as a profession is vested with the knowledge and responsibility of providing holistic and quality care at every level of service delivery. The major challenge of nurses is to ensure that quality nursing care is provided to all patients. Quality nursing care is the established target of nursing intervention and actions to ensure that each patient receives the agree level of care. According to Cronenwett, Sherwood, Bamsteiner, Disch, Johnson, Mitchell, Taylor, Sullivan \& Warren (2007) states that, the nurse as chief architect of patient care, sets the tone for the practice environment. This implies that health providers seek workplaces that embrace quality and places were good work is recognized.

Ensuring quality nursing care is a challenge because of limited financial resources, inadequate number of nurses and the fast growing population as well as increased attendance in hospitals especially in teaching hospital Calabar, Inadequate supply of drugs, poor leadership and control on the part of the nurses, lack of equipments and materials to use, and filthy environment, all these leads to low quality nursing care. The knowledge and practice of quality nursing care cannot be over emphasized. It is the right of the patients of health services to demand the best of knowledge of quality nursing care from nurses. Quality was defined by the institute of medicine as the degree to which health services for individuals and populations increase the likelihood of desired health outcomes and are consistent with current professional knowledge (Lohr \&Schroeder 1990). 
It is widely recognized that nursing care is very important so that any slight mistake from nurses while rendering treatment and care may result in death of the patients. This is why the management of University of Calabar Teaching Hospital (UCTH) are so worried concerning the type of quality care that is render to our patients now took it upon themselves to always remind nurses of their obligations through continuing education, workshops, seminars, and conferences.

Inspite of that, the situation still remain the same, observation has shown that, the nurse is expected to provide preventive, promotives, curative and rehabilitative care to individual and their families or groups within the community, thereby enhancing quality nursing care which is not found always among most nurses in University of Calabar Teaching Hospital (UCTH).

The depth and the extent of this problem shows that quack nurses will take over the profession as nurses do not know that they are the builders of clinical settings. On every report of dissatisfaction as low as 5\% should be taken seriously as that will improve upon the nurses' knowledge concerning what the patients want and the negative outcome will be seen by the patients.

The fact remains that knowledge practice and outcomes is one of the most important findings that nurses will need to know about from their individual patients. This is because in today's competitive environment with high production and service standards, patients expect nurses to perform at a satisfactory level as group of people who have the knowledge and care to practice well with a positive outcome in order to facilitate the quality of nursing care among nurses. Besides, nurses should be encouraged on self-development so that they can continue to be clients advocate.

This is why the researchers are interested to investigate on knowledge practice and outcome of quality nursing care among nurses in University of Calabar Teaching Hospital (UCTH).

\subsection{Statement of Problem}

Knowledge is a subjective measure of quality nursing care, and is often criticized by patients because a patient hospitalized for surgery may receive excellent health care with good outcome but may be dissatisfied with the interpersonal care received from nurse as well as the food and facilities provided. Therefore knowledge with nursing care however is increasing recognized as an important dimension of quality nursing care.

Besides, many factors have prevented nurses from carrying out quality nursing care such as poor working environment, inadequate drug supply, nurses' shortage, high increase attendance of patients in the hospital with few nurses, poor leadership and control on the part of nurses, lack of equipment and material to use and poor sanitation of the environment all this, lead to low quality nursing care and the need for the study on knowledge practice and outcome of quality nursing care among nurses in University of Calabar Teaching Hospital (UCTH).

\subsection{Purpose of the Study}

The purpose of this study was to determine knowledge practice and outcome of quality nursing care among nurses in University of Calabar Teaching Hospital (UCTH).

\subsection{Objective of the Study}

1) To identify the level of nurses knowledge on the quality of nursing care in University of Calabar Teaching Hospital.

2) To assess nurses practice on the quality of nursing care render to patient in University of Calabar Teaching Hospital.

3) To identify patients outcome on the quality nursing care render to patient by nurses in University of Calabar Teaching Hospital.

\subsection{Research Questions}

1) What is the level of nurses' knowledge associated with the quality nursing care render to patient in University of Calabar Teaching Hospital?

2) What is the level of practice by nurses associated with the quality nursing care render in University of Calabar Teaching Hospital?

3) What is the outcome of patient associated with the quality nursing care render in University of Calabar Teaching Hospital?

\subsection{Hypothesis}

There is no significant influence of knowledge on the practice of quality nursing care among nurses in University of Calabar Teaching Hospital. 


\subsection{Importance of the Study}

The study might be of benefit to the following nurses' patients and researchers.

Nurses: It may help health workers to appreciate where the problem is related to low quality nursing services or care.

Patients: Patients might be assure that health workers found in the hospital are able to render quality nursing care.

Researchers: It will reveal gaps in the knowledge practice and outcome of quality nursing care among nurses in the hospital.

\subsection{Goals}

The goal of this study is to make sure that quality nursing care is continuously rendered to each and every patient that visit the hospital or during hospitalization.

\section{Review of Related Literature}

\subsection{Nurses' Knowledge of Quality Nursing Care}

Nursing practice is team based, and therefore nursing students and staff nurses are to be equipped with knowledge for proper understanding of the care of their clients. This knowledge is supposed to be applied in care giving by the nurse through proper understanding of rational care and prompt nursing interventions. The clinical environment of the client may change and the nurse will not be required to insist on routine nursing care, but may have to apply critical thinking to device another intervention method based on another theory. Therefore education in theory application is advocated based on knowledge (Ihekwaba, 2009).

A nurse in the clinical setting must be intelligent and be able to make quick decisions based on findings. These decisions are often life-saving. She stands to advice other team members based on the client's condition skills in critical thinking. This involves application of reasonable question that will help elicit new information to replace old ones. This method of questioning is referred to as Socratic questioning which helps the clinical nurse to reason beyond the physical, especially when the patient's situation is inconsistent. This should be applied when taking reports about the client. Therefore every clinical nurse should be alert and functional. The nurse clinician should be able to make a generalization based on findings which will help her in making changes in her implementation and reevaluation (Brunner \& Suddarth, 2008).

Here the clinical nurse works based on conceptual framework which helps her to interpret the clients condition and also make changes to sustain the professional standards and ethics. To achieve this, students need to imbibe not just the skills but professional values. Students need to be evaluated on their challenges in performing the clinical role of the nurse as the technological development with computerized monitoring and documentation have made clients are more knowledgeable about their rights (Brunner \& Suddarth 2008).

Brunner \& Suddarth (2008) agree that nurses' role is broad based because she has to identify and treat human reactions to stimuli in health and illness. Hamric (2000) opine that the role of the nurse depends on the needs of the client and his/her environment. Watson \& Ray (2005) observed that the growth in the nurses' role and its undefined nature warrants the nurse-clinician to have exposure, using both nursing and medical skills in obtaining baseline data needed for further diagnosis and treatment of client. Nurse patient interaction is however guided by the professional code of conduct.

This involves a host of activities which are rationalized with the goal of helping clients to wellness. This originated from the Florence Nightingale era whose effort was credited for improving care in the hospital setting. Clinical nurses' roles are involved in direct client care whose function depends on the need of the client.

The nurse is encouraged to be everything to the client that is the spirit of dynamism. However, there are basic functions expected of a clinical nurse, such as;

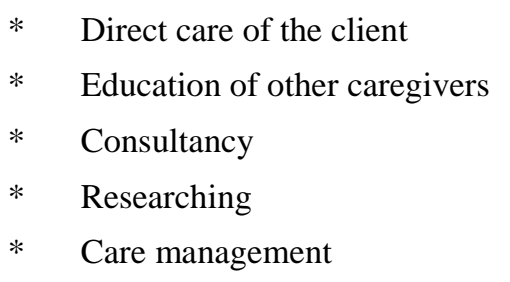

These functions may vary depending on the environment, culture and location.

Direct care of the client: This aspect of nurses' role like others have regenerated from mere provision of comfort to client, reassurance and provision of needs and use of nursing procedure with little knowledge of rational, making care 
giving mechanical under apprenticeship, to todays' care giving which is scientific and involves application of the liberal knowledge of science acquired by the student nurse during training. It involves a holistic application of knowledge based on skill founded on theories of nursing. It is now advocated that it must be ensured that every nursing procedure or technique is based on an underlying theoretical framework. However, the dynamic nature of nursing implies that clinical functions must be based on not just scientific theories but on an ecclesiastical standard that originates from physical, psychosocial, developmental, cultural and spiritual orientation of the client.

The nursing process is therefore a tested and approved tool for achievement of this standard of care and has been taught and implemented in the clinical setting. This is an important aspect of nursing practice in which the nurse does not just depend on classroom, knowledge and routine nursing care but a virtue required when a prompt decision has to be taken in a crisis situation. Here a quick evaluation and application of previous knowledge is done often in life saving situation. Student nurses are therefore encouraged to practice and develop critical thinking skill.

The clinical nurses as a teacher: a client who has just been diagnosed of a disease condition is a novice that will need to gradually become an authority in his own condition. In such a situation, the clinical nurse has the role and responsibility to carry the client along during the care giving, thereby getting him to know about his condition. They both work toward rehabilitation and home management of the client on discharge. As the nurse applies nursing process and draws a care plan, she assesses the client's educational level and ability to learn. The relations and other significant members of the client's family are incorporated into the care programme.

Goal of care is set by client and the nurse, and then intervention and other components of care plan will follow. The new trend in care giving is holistic, evidence based, practical and result oriented. The nurse uses effective communication skills to coordinate care. Student nurses are therefore groomed to fit into the contemporary standard of care.

This role is more applicable to the nurses in the western world. This goes to buttress the fact that nurses' role varies depending on environment. In our indigenous setting, the consultancy role of the nurse is still in the teething stage. She however consults in the midst of her subordinates by assuming a leading and directing position. The student nurses and other junior nurses consult the senior nurse for direction and guidance, where as in the USA the Nurse Clinician actually consults in the clinic with the other care givers.

Nursing research is widely advocated to ensure standard and professionalism. Every nurse is encouraged to embark on research in her unit of function. Nurses should appropriately research into their daily practices for new discoveries and changes, and such researches should be published and used to improve standard of care. It is a pre-requisite in professionalism (Sherwood \& Barnsteiner, 2012). Akpabio (2008) had suggested that research helps to improve the standard of care and called on clinicians to join the nurse educators in researching.

Brunner \& Suddarth (2008) observed that nurse clinicians are research consumers who use research findings to improve the quality of care. They pointed out the need for nurse-clinicians to have awareness about research and its process, so that they can protect the clients by insisting on their human rights during research. However, clinicians can indicate researchable problems around them.

This seems to be one of the known functions of a clinical nurse. They perform management roles in care giving. The nurse is the clients host and sees to the total care to the client. She is the one present with the client all the time. This role starts from management of the care-giving team by use of skills like communication, advisory suggestions, supervision of subordinates and advocating for the client. The manger has administrative training and allocates function to other nurses and care-givers under her as well as ensures the day to day running of the clinical area. The student nurse sees the care manager as her professional role model and aims at acquiring such levels of professional skills (Ihekwaba, 2009).

\subsection{Nurses' Practice of Quality Nursing Care}

The nurse should carry out professional commitments and activities with meticulous care, with a generous measure of performance, and with fidelity toward those whom she serves. Honesty, understanding, gentleness, and patience should characterize all of the acts of the nurse. A sense of the fitness of things is particularly important (ANA, 1940).

The nurse has a basic concern for people as human being, confidence in the fundamental power of personality for good, respect for religious beliefs of others, and a philosophy which will sustain and inspire others as well as herself (ANA, 1940). The nurse provides services with respect for the dignity of man, unrestricted by considerations of nationality, race, creed, color or status (ANA, 1968).

In addition to signaling the uniqueness of each recipient of nursing care (then newly termed "the client"), the 1976 code also recognized that things other than nationality, race, creed, colour and status can result in unacceptable differences in treatment. This provision remained the same in the 1985 Code. In the 2001 revision, the scope was broadened to include 
"inherent dignity (a critical modifier), worth, and uniqueness". A significant addition was the phrase "practices with compassion and respect". The addition of the virtue compassion was related to the serious scholarship currently being done by nurse ethicists in virtue theory and care ethics.

The nurse in all professional relationships, practice with compassion and respect for the inherent dignity, worth and uniqueness of every individual, unrestricted by considerations of social or economic status, personal attributes, or the nature of health problems (ANA, 2001).

In every human encounter, we convey one of three messages: (1) Go away, my world would be better without you; (2) You are an object, a task to be done, you mean nothing to me; or (3) You are a person of worth, I care about you. The more vulnerable people are, the more we can become their world of meaning. Since disease, injury, and illness can separate people from affirming experiences that enhance their sense of worth (family relationship, work, other achievements), how we present ourselves as health professionals to individuals needing truly matters. A quick moment of reflection will help you to identify individuals in your own life whom you perceive as being either therapeutic or toxic presence? What do you leave in your wake: affirmation, peace, joy, warmth, support, the experience of being cared about as well cared for? In healthcare settings, it is critical for nurses to relate to patients as a healing presence. Two stories follow to illustrate this point.

\section{Example}

Jean Thatcher is a morbidly obese, 47-year-old, single, white attorney with multiple sclerosis. She is frequently admitted to your hospital for complications related to her multiple sclerosis and obesity. Since she quickly "exhausts" the patience and best efforts of the staff, she is "rotated" among several units all of whom know her well and loathe her inpatient stays on their unit. The staff's best efforts to educate her about appropriate self-care and preventive practices have fallen on deaf ears. She refuses to cooperate when her support is elicited for bathing, position changes, and the like. Her one visitor, her mother, believes that the staff discriminates again her daughter and complains frequently to management. Both the patient and her mother frequently threaten to sue the hospital for neglect and discrimination. Jean admits that she is refusing to eat or help with bathing and positioning. She said she has "had enough" and wants to give up. Most of the staff have already "given up" and ask "why we should we try to help Jean when she has been clear about not wanting our help?" Today, one nurse was overheard saying, "I'm not going to sprain my back trying to get her to move when she refuses to cooperate. She can lie in her filth for all I care." The nurse manager calls a meeting to explore how the team can best respond to the challenges of caring for Ms. Thatcher. In what practical ways does Provision 1 of the Code of Ethics influence the standard of care for Ms. Thatcher and similar patients? Is Ms. Thatcher's wish to "give up" an autonomous act of self-determination that should be supported by her nurses?

The nurse-patient relationship creates the basic unit in which much of nurse practice and ethics occurs. A nurse's ethical sensitivity is the first requirement in application of this provision that places the patient at its center. Sometimes, nurses define a problem as a clinical one without seeing the ethical aspects in it. If ethical issues that exist are missed, then that part of the situation is not attended by the nurse. If the nurse is clinically competent, but ethically insensitive or oblivious, then this provision will not have a part in the decision making and actions that are needed to deal with the whole patient situation. If nurses are sensitive to the ethical issues or concerns involved in a given situation, the next step is them to pay attention to their own reactions to this situation. This reaction informs the nurse that something is wrong or missing ethically. This sensitivity and intuitive reaction comes from our values and socialization as children into adulthood. This informal, basic ethics education is further developed in nursing school where students are taught and socialized into the values and ethics of nursing. Sometimes these values are deep enough that we may not be aware of them until they arise in a specific situation. It is at this point that one needs to examine both the situation and the reaction that one has had to it more closely.

To examine the ethics of the situation, one needs some way of viewing the ethical issues. This calls for knowledge of the clinical situation, the people involved, and the patient's values and wishes. Nurses can use ethical principles, such as respect for patient autonomy, non-maleficence (the non-infliction of harm), beneficence (or doing good), justice, truth telling, and promise keeping (Beauchamp \& Childress 2001). To use these principles, one needs some understanding of what each of these principles mean and how they interact. This requires basic ethics education. For example, the ethical principle "respect for autonomy" is very important, but it is not absolute. This means that, in some limited and carefully thought-out situations, patient autonomy can be overridden in the service of another, more stringent, ethical principle, to do no harm. In using the ethical principle "do no harm" to override a patient's autonomous choice, health professionals need to be very clear that it is the patient who is being kept from harm and not the care-giving staff. Additionally, it is so much "easier" simply to tell people what they should do than to explain their clinical situation to them and have them participate in the decision making process. This is true whether the patient is an individual, family, group, or community.

By creating easy situations for healthcare professionals is not what ethics is about Nurses use ethical principles such as "respect for autonomy", "do not harm", and "doing good" as they engage in ethical reflection and deliberation. They also 
use aspects of "caring ethics" that is developing as an alternative ethical theory. These aspects are: attentiveness, responsibility, competence, and responsiveness.

Ethical problems often relate to the tensions between responsibilities, as well as the multiple commitments of people who live or work in a network of relationships. It becomes necessary to interpret the different viewpoints of all those involved with an ethical problem. It is also necessary to understand that our own values and obligations, loyalties, and ideals arise from multiple sources, as do those of others. In situations with people from cultures that differ from that of the nurse, value and obligation structures that come into play can be further complicated. Values underlie our ethical analyze, choices, and actions. Not all values are shared; thus, different people may choose or act in ways that would not be the choices or actions of the nurse. What may seem strange to one person may be perfectly reasonable to another, given that person's world view, culture, and values (Davis, 2003).

When nurses deal with a group or community as the patient, notices of justice may come into play. Where resources are limited or managed, the principle of distributive justice is particularly important. Distributive justice refers to the sharing of burdens and benefits in the allocation of rationing. Customarily terms such as "fair", "equitable", "just", and "fitting" are used with regard to "justice" in the distribution of resources. The nurse needs to think through how to be fair in any issue of resource allocation, including the nurse's skill and attention or time.

\section{Example}

The national nursing shortage problem has arrived at the local hospital and the Vice President for Nursing is having difficulties staffing all units adequately, even though two units have been closed altogether. She can either spread the nurses around the hospital and keep all the remaining units open with fewer nurses on each unit than is really safe, or she can close some additional units and place those nurses on other units to have an adequate nursing staff.

This choice would be safer for admitted patients, but other patients could not be admitted due to closed units. In order to reason through this problem or resource allocation, the nurse administrator must rely on the ethical principles of justice, non-maleficence, and beneficence. This VP for Nursing must consider the welfare of the institution, the nursing staff, and the patients. How would you assess this situation morally?

In your ethical analysis, what would be acceptable options? What would not be acceptable? How might the Code for Nurses inform the VP's decision? What choice of action might promote the most good while creating the least harm?

The nature of phenomena to which the actions of nurses are directed is ascertained by assessment in its various forms, such as observation, interviewing, measurement, and the like. Instruments for the measurement of conditions within the purview of nursing are being developed and tested through nursing research.

Diagnose: Diagnosis is a beginning effort to objectify a perceived difficulty or need by naming it, as a basis for understanding and taking action to resolve the concern. A nurse's conceptualization or diagnosis of a presenting condition is a way of ascribing meaning to it, which may or may not accurately reflect the phenomenon under consideration for treatment. Both the diagnosis and its theoretical interpretation are open to revision; indeed, in some modalities, such as psychotherapy, diagnostic revision is simultaneous with the ongoing therapeutic work.

Theory: Nurses use theory in the form of concepts, principles, processes, and the like, to sharpen their observations and to understand the phenomena within the domain of nursing practice. Such understanding precedes and serves as a basis for determining nursing actions to be taken. The theoretical base for nursing is partially self-generated and partially drawn from other fields; the resulting insights are integrated into a foundation for nursing practice. Nursing is primarily an applied science: it uses the results of nursing research (which tend to be specifically related to the human responses of concern to nurses) and it selects theories from many other sciences on the basis of their explanatory value in relation to the phenomena nurses diagnose and treat. The range of theories nurses use includes intrapersonal, interpersonal, and systems theories. Intrapersonal theories explain within-person phenomena. Interpersonal theories aid understanding of interactions between two or more people. Systems theories provide explanations of complex networks or organizations, the dynamics of their parts and processes in interaction. Use of this range of theories is necessary because the various conditions within the purview of nursing cannot be understood in terms of cause-effect relations only, but also requires knowledge of system dynamics, pattern and process interactions. When responses to actual health problems are being treated, the nature of the difficulty and its causes (when known) require theory application for full understanding of extant problems. When response to potential health problems or maintenance of health are the focus for the nursing action, theories that aid conceptualization of optimal functioning of individual capacities and processes and of the dynamics of human systems are applied to determine reordering of behavior or life styles congruent with healthy living. Thus, theory selected for application in nursing practice is chosen for its relevance to the task at hand. The ideas and theories of the individual practitioner influence nursing practice in focus and action. Ideally, the actions of the nurse 
are taken from a theoretical base that includes an accurate understanding of the phenomena in question and a means for evaluation or readjustment.

\section{Actions}

The aims of nursing actions are to ameliorate, improve, or correct conditions to which those practices are directed, to prevent illness, and to promote health. Ideally, actions are taken on the basis of understood fact (phenomena). In carrying out nursing care, highly developed technical and interpersonal skills are equally as important as the sensitive observation and intellectual competencies required for the nurse in the nursing situation to arrive at a diagnosis (explanation of a problem at hand) and determination of beneficial nursing actions to be taken. Treatment of a diagnosed condition involves nursing actions that can be described and explained theoretically as to then-relation to phenomena and expected outcome (Davis, 2003).

\subsection{Outcome of Quality Nursing Care}

Effects: Nursing actions are intended to produce beneficial effects in relation to identified responses. It is the results of the evaluation of outcomes of nursing actions that suggest whether or not those actions have been effective in improving or resolving the conditions to which they were directed. The results of research study of the relation of particular actions to specific phenomena, determined under controlled conditions, provide more rigorous scientific evidence of beneficial effects to nursing actions than does periodic evaluation or testimonials as to effectiveness.

Nursing values an approach to practice in which investigation and action are interrelated. This approach is apparent in the four characteristics of nursing, which have been described, and is reflected in the use of the nursing process, which serves as an organizing framework for practice.

The nursing process encompasses all significant steps taken in the care of the patients, with attention to their rationale, their sequence, and relative importance in helping the patient reach specified and attainable health goals. The nursing process requires a systematic approach to the assessment of the patient's situation, which includes reconciliation of patient/family and nurse perceptions of the situation; a plan for nursing actions, which includes patient/family participation in goal setting; joint implementation of the plan; and evaluation which includes patient/family participation. The steps in the process are not necessarily taken in strict sequence beginning with assessment and ending with evaluation. The steps may be taken concurrently and should be taken recurrently, as in the evaluation of the assessment or the plan of action.

Recognition of the nursing process is reflected in the ANA Standards of Nursing Practice, which apply to all nursing practice. These standards, published by the professional society in 1973, provide one broad basis for evaluation of practice and reflect recognition of the rights of the person receiving nursing care. The standards describe a "therapeutic alliance" of the nurse and the person for whom she or he provides care through use of the nursing process.

The characteristics of phenomena and theory application are implicit in the standards involving data collection, diagnosis, and planning; that of action is referenced in the standards involving planning and treatment; and the characteristic of effects is related to the standards involving evaluation and revision (Davis, 2003).

There is anecdotal evidence that nurse's moral distress affects quality of patient care and subsequent health outcomes. Nurses who frequently experience moral distress are at risk of decreased productivity, leading to decreased self-esteem, wholeness and ultimately loss of the ability to give good patient care (Sherwood, \& Barnsteiner,(2012). Nurses described situation in which they avoid patients who were over solicitous on them because they felt guilty about what happening to them (Reina, \& Barden 2007). Other effects on patients were increased pain, longer hospital stay and inadequate and inappropriate care (Sherwood, \& Barnsteiner, 2012). Some nurses used negative coping tactics to manage ethical distress, including distancing and escape avoidance strategies towards patient (Reina, \& Barden, 2007).

Moral distress has also been associated with loss of moral integrity in nurses (Williams, 2004) and is a powerful, overall impediment to ethical practice (Hamric, 2000). The term moral integrity means soundness, reliability, wholeness, and integration of moral character over time. This signifies being faithful to coherent, integrated moral values and actively depending on them when they are threatened. A person of moral integrity is not disordered or disoriented by moral conflict and is faithful to the standards of the common morally as well as to personal moral ideas (Beauchamp,\& Childless, 2001). Deficiencies in moral integrity represent a break in the connection between moral convictions and actions. Moral distress may be a direct result of what nurses perceive as their participation in moral wrong doing.

\subsection{Conceptual Framework}

\section{Abedellah's Theory}

The nursing theory developed by Faye Abdellah et al (1960) emphasizes delivering nursing care for the whole person to meet the physical, emotional, intellectual, social, and spiritual needs of the client and family. 


\section{Application to the Study}

When using this approach, the nurse needs knowledge and skills in interpersonal relations, psychology, growth and development, communication and sociology, as well as knowledge of the basic sciences and specific nursing skills. The nurse is a problem solver and decision-maker. The nurse formulates an individualized view of the client's needs, which may occur in following areas.

- Comfort, Hygiene, and safety

- Physiological balance

- $\quad$ Physiological and social factors

- Sociological and community factors

In these four areas, Abdellah et al (1960) identified the following specific client needs, which are often referred to as Abdellah's 21 nursing problems.

- To maintain good hygiene and physical comfort

- $\quad$ To achieve optimal activity, exercise, rest, and sleep

- To prevent accident, injury, or other trauma and prevent the spread of infection

- $\quad$ To maintain good body mechanics and prevent and correct deformities

- To facilitate the supply of oxygen to all body cells

- $\quad$ To facilitate the maintenance of nutrition to all body cells

- $\quad$ To facilitate the maintenance of elimination

- To facilitate the maintenance of fluid electrolyte balance

- To recognize the physiological responses of the body to disease conditions-pathological, physiological and compensatory

- To facilitate the maintenance of regulatory mechanisms and functions

- To facilitate the maintenance of sensory function

- $\quad$ To identify and accept positive and negative expressions, feelings, and reactions

- To facilitate the maintenance of effective verbal and nonverbal communication

- $\quad$ To facilitate the development of productive interpersonal relationship

- To facilitate progress toward achievement of personal spiritual goals

- To create and/or maintain a therapeutic environment of personal spiritual goals

- To create and/or maintain a therapeutic environment

- To facilitate awareness of the self as an individual with varying physical, emotional, and development needs

- $\quad$ To accept the optimum possible goals in light of limitations-physical and emotional

- To use community resources as an aid in resolving problems arising from illness

- To understand the role of social problems as influencing factors in the cause illness. This is all what the patient need from the nurse in carrying out quality nursing care as a professional who have knowledge practice and a better outcome.

\section{Methods}

The focused of methods in this study and procedure adopted by the researchers in collecting data for the study are under the following sub-headings.

\subsection{Research Design}

The research design adopted in this study was survey. In a survey design, according to Isangedighi, Joshua, Asim \& Ekuri (2004), the researchers attempts to obtain a picture of the present conditions of particular phenomena. It is directed towards determining the nature of a situation, as it exists at the time of investigation and it depends basically on questionnaire as means of data collection. This particular research design was adopted because the variables under study were examined as they existed when the study was carried out. The study also involves populations that were only covered through a sample using questionnaires and describing the picture of the situation instead of drawing inference. 
In this study, the independent variables, knowledge, attitude of quality nursing care was a measure of difference; while dependent variables already exist in the outcome of quality nursing care to patients

\subsection{Research Setting}

This study was carried out in University of Calabar Teaching Hospital, Calabar. University of Calabar Teaching Hospital is a Tertiary Health Institution, founded in 1979; and is located at the south-east of Calabar. The hospital is made of three (3) annexes; permanent site, maternity and comprehensive health care Okoyong. The hospital renders the following services, clinical, man power development (teaching of nursing, paramedical and medical students) and research.

The permanent site being the main study area is the heart of the hospital and comprises of both the administrative offices and the clinical wards of the hospital and the maternity wards like labour ward, antenatal, post-natal, special baby care unit and gynae ward which are also located at the permanent site for quality nursing care.

Permanent site is located along Eastern high way behind University of Calabar. The permanent site of the hospital is bounded on the east by Unical Hotel, on the west by Qua River (Esuk Atu) and on north by Calabar International Airport. The University of Calabar Teaching Hospital is currently made up of 600 beds which are distributed among the three (3) annexes and has staff strength of about 550 nurses.

\subsection{Population of the Study}

The target population of this study comprised of all the nurses that are working in UCTH and patients admitted in the ward between 2013 and 2014. Total population for the study was 550 nurses and all the patients in the hospital. Out of this number, 140 nurses and patients were used 20 from each ward for both patients and nurses.

\subsection{Sample Size}

The sample size for this study was 140 nurses and patients who were in the ward using 140 questionnaires constructed and issue out for respondent to answer.

\subsection{Sampling Technique}

A random sampling technique was used to obtain the required sample for nurses and patients who participated in the study. This was done to give each nurse and patient equal opportunity of being selected through balloting of YES or NO.

\subsection{Instrument for Data Collection}

The instrument used for data collection was direct face to face contact with the respondents. The researcher also used structure questionnaire to obtain data collection from respondents.

\subsection{Validity of Instrument}

The researcher structured the questionnaire gave to her colleagues to go through it and then to her supervisor for necessary correction and inputs. The questionnaire was read and re-read over and over again so that at face value the instrument looks valid; my supervisor also checked face validity of the questionnaire and approved them for typing. The questionnaire were submitted to the project supervisor after they were designed by the researcher who after checking for content validity whether it measured what it supposed to measure and approved them for typing.

\subsection{Reliability of the Instrument}

In order to test the reliability of the instrument a pilot study was carried out on ten hospitalized patients in General Hospital, Calabar.

A test re-test reliability method was used in determining the reliability of the instrument. Here the questionnaire was administered on the respondents and after one week it was again administered on the same respondents and Pearson product moment correlation coefficient was calculated as presented in table 1.

Table 1. Test re-test reliability of knowledge, practice and outcome among nurses in UCTH ( $\mathrm{n}=10)$

\begin{tabular}{llllll}
\hline Variable & No. of items & Testing & X & SD & r \\
\hline Nurses knowledge of quality care & 6 & $1^{\text {st }}$ & 19.72 & 1.98 & 0.98 \\
& & $2^{\text {nd }}$ & 20.90 & 2.48 & \\
Practice of quality nursing care & 5 & $1^{\text {st }}$ & 20.42 & 3.10 & 0.85 \\
& & $2^{\text {nd }}$ & 22.81 & 3.78 & 0.74 \\
Patient outcome of quality care & 7 & $1^{\text {st }}$ & 21.68 & 3.14 & 0.74 \\
& & $2^{\text {nd }}$ & 18.78 & 1.90 & \\
\hline
\end{tabular}




\subsection{Procedure for Data Collection}

An introductory letter was issued by the school authority to the hospital for permission to collect data. Also a sample of questionnaire was attached to the letter, this enabled the researcher to collect data for study conveniently.

\subsection{Procedures for Data Analysis}

Data was collected through the use of questionnaire. Descriptive statistics was used to reduce masses of raw data into a more meaningful form. And data presented in tables using percentages and frequencies.

\subsection{Ethical Consideration}

Based on this research work the ethical issues involved were privacy of respondents, their right respected as well, their names and identity were avoided as seen in the first part of the questionnaire. The issue of plagiarism was not over look as well the literature and texts used were cited with their authors and data accordingly, hence acknowledge their contributions to this research work. Strict confidentiality was maintained.

\section{Result}

The main purpose of this study is the analysis of data and the presentation of results. This is done under the following sub-headings;

\subsection{Socio-demographic Data}

The socio- demographic data of the respondents is as presented in Table 2 below.

Table 2. Socio-demographic data of respondents

\begin{tabular}{lll}
\hline & Frequency & percentage \\
\hline Age: & & 32.8 \\
18-22 years & 46 & 37.2 \\
23-30years & 52 & 30.0 \\
31years-Above & 42 & 100 \\
Total & 140 & 24.2 \\
Marital Status: & & 45.0 \\
Single & 34 & 21.9 \\
Married & 63 & 17.9 \\
Divorced & 18 & 100 \\
Separated & 25 & 23.6 \\
Total & 140 & 26.4 \\
Rank: & & 22.1 \\
Staff Nurse Midwife & 33 & 16.4 \\
Nursing Officer 1 & 37 & 7.2 \\
Matron & 31 & 4.3 \\
Chief Matron & 23 & 100 \\
ADNS & 10 & 87.1 \\
DNS & 6 & 8.6 \\
Total & 140 & 4.3 \\
Religion: & & 100 \\
Christianity & 122 & \\
Islam & 12 & 6 \\
Traditional Religion & 140 & \\
\hline
\end{tabular}

The socio-demographic data of respondents as presented in Table 2 indicates that 46(32.8\%) of them were aged 18-22 years, 52(37.2\%) were 23-30 years, $42(30 \%)$ were 31 years and above. Their marital status show that $34(24.2 \%)$ were single, $63(45.0 \%)$ were married, $18(12.9 \%)$ were divorced while $25(17.9 \%)$ of them were separated. Their rank indicate that $33(23.6 \%)$ were staff nurse midwives, $37(26.4 \%)$ were nursing officer $1,31(22.1 \%)$ were matrons, $23(16.4 \%)$ were chief matrons, $10(7.2 \%)$ were ADNS while 6(4.3\%) were DNS. On their religion, 122(87.1\%) were Christians, 12(8.6\%) were Muslims while 6(4.3\%) practiced traditional religion.

\subsection{Research Question by Research Question Presentation of Results}

\section{Research Question 1:}

What is the level of nurses' knowledge associated with the quality of nursing care rendered to patients in university of Calabar teaching hospital?

This research question is answered using frequencies and percentages as presented in table 3 . 
Table 3. Nurses' knowledge of quality care rendered to patients.

\begin{tabular}{|c|c|c|c|}
\hline $\mathrm{S} / \mathrm{N}$ & & Yes & No \\
\hline 1 & Nurses have knowledge of admission? & $\begin{array}{l}98 \\
(70.0)\end{array}$ & $\begin{array}{l}42 \\
(30.0)\end{array}$ \\
\hline 2 & Nurses have knowledge of health education? & $\begin{array}{l}97 \\
(69.3)\end{array}$ & $\begin{array}{l}43 \\
(30.7)\end{array}$ \\
\hline 3 & Nurses have knowledge of medication? & $\begin{array}{l}89 \\
(63.6)\end{array}$ & $\begin{array}{l}51 \\
(36.4)\end{array}$ \\
\hline 4 & Nurses have knowledge of intra and interpersonal relationship? & $\begin{array}{l}85 \\
(60.7)\end{array}$ & $\begin{array}{l}55 \\
(39.3)\end{array}$ \\
\hline 5. & Nurses have knowledge of prevention of infection? & $\begin{array}{l}92 \\
(65.7)\end{array}$ & $\begin{array}{l}48 \\
(34.3)\end{array}$ \\
\hline 6. & Nurses do not have knowledge of supporting patients during hospitalization? & $\begin{array}{l}42 \\
(30.0)\end{array}$ & $\begin{array}{l}98 \\
(70.0)\end{array}$ \\
\hline
\end{tabular}

Note: Numbers in parentheses are percentages.

The result of data presented in table 3 shows that $98(70 \%)$ of the respondents indicate that nurses have knowledge of admission while $42(30 \%)$ indicated that they do not.97(69.3\%) indicated that nurses have knowledge of health education while $43(30.7 \%)$ indicated that they do not. $89(63.6 \%)$ indicated that nurses have knowledge of medication while 51(36.4\%) indicated that they did not.85(60.7\%) indicated that nurses have knowledge of intra and interpersonal relationship while 55(39.3\%) indicated that they do not.92(65.7\%) indicated that nurses have knowledge of prevention of infection while $48(34.3 \%)$ indicated that they do not.42(30\%) indicated that nurses do not have knowledge of supporting patients during hospitalization while $98(70 \%)$ indicated that they do.

From the above responses, it can be concluded that nurses at the University of Calabar teaching hospital have knowledge associated with the quality of nursing care rendered to patients at the hospital.

\section{Research Question 2}

What is the level of practice by nurses associated with the quality nursing care rendered in University of Calabar Teaching Hospital?

This research question is answered using frequencies and percentages as presented in table 4 .

Table 4 . Practice of quality nursing care by nurses

\begin{tabular}{|c|c|c|c|}
\hline $\mathrm{S} / \mathrm{N}$ & & Yes & No \\
\hline 1 & Do nurses assess patients during hospitalization? & $\begin{array}{l}97 \\
(69.3)\end{array}$ & $\begin{array}{l}43 \\
(30.7)\end{array}$ \\
\hline 2 & Do nurses diagnose the problems of the patient? & $\begin{array}{l}92 \\
(65.7)\end{array}$ & $\begin{array}{l}48 \\
(34.3)\end{array}$ \\
\hline 3 & Do nurses intervene during hospitalization? & $\begin{array}{l}88 \\
(62.9)\end{array}$ & $\begin{array}{l}52 \\
(37.1)\end{array}$ \\
\hline 4 & Do nurses document and report patients' problems? & $\begin{array}{l}84 \\
(60.0)\end{array}$ & $\begin{array}{l}56 \\
(40.0)\end{array}$ \\
\hline 5. & $\begin{array}{l}\text { Availability of the equipment in the hospital help nurses to practice quality } \\
\text { nursing care? }\end{array}$ & $\begin{array}{l}95 \\
(67.9)\end{array}$ & $\begin{array}{l}45 \\
(32.1)\end{array}$ \\
\hline
\end{tabular}

Note: Numbers in parentheses are percentages.

Result of data presented in table 4 shows that 97(69.3\%) of the respondents indicated that nurses do assess patients during hospitalization while $43(30.7 \%)$ indicated that they do not, 92(65.7\%) indicated that nurses diagnose the problems of the patients while $48(34.3 \%)$ indicated that they do not, $88(62.9 \%)$ indicated that nurses do intervene during hospitalization while 52(37.1\%) indicated that they do not, $84(60 \%)$ indicated that nurses do document and report patients' problems, while 56(40\%)indicated that they do not,95(67.9\%) indicated that availability of equipment in the hospital helps nurses to practice quality nursing care, while 45(32.1\%) indicated that it does not.

Based on the data presented above, it is concluded that nurses at the University of Calabar Teaching Hospital Practiced Quality nursing care.

\section{Research Question 3}

What is the outcome of patients associated with the quality of nursing care rendered at University of Calabar Teaching Hospital?

This research question is answered using frequencies and percentages as presented in table 5 . 
Table 5. Patient outcome of quality care

\begin{tabular}{llll}
\hline S/N & & Yes & No \\
\hline 1 & Did you recover from your sickness after admission? & 99 & 41 \\
& & $(70.7)$ & $(29.3)$ \\
2 & Will you attribute your recovery to care given to you by nurses? & 97 & 43 \\
& & $(69.3)$ & $(30.7)$ \\
3 & Where you well taken care of, by nurses during hospitalization? & 82 & 58 \\
& & $(58.6)$ & $(41.4)$ \\
4 & Have you ever sign against medical advice as a result of your sickness during & 44 & 96 \\
& hospitalization? & $(31.4)$ & $(68.6)$ \\
5. & Did you decline because of nurses' lack of care/support? & $(18.6)$ & $(81.4)$ \\
& & 94 & 46 \\
7 & Will you ever visit hospital next time if you have problem? & $(67.1)$ & $(32.9)$ \\
& & 93 & 47 \\
\end{tabular}

Note: Numbers in parentheses are percentages.

The result of findings as presented in table 5 indicate that $99(70.7 \%)$ of the respondents indicated that they recovered from their sickness after admission while 41(29.3\%) did not, 97(69.3\%)indicated that they will attribute their recovery to care given to them by nurses while $34(30.7 \%)$ did not. $82(58.6 \%)$ indicated that they were well taken care of, by nurses during hospitalization while 58(41.4\%) indicated that they were not, 44(31.4\%) indicated that they had signed against medical advice as a result of their sickness during hospitalization while $96(68.6 \%)$ indicated that they had not, $26(18.6 \%)$ indicated that they declined because of nurses' lack of care/support while $114(81.4 \%)$ indicated that they did not, 94(67.1\%) indicated that they will ever visit hospital next time if they have problem while 46(32.9\%) indicated that they will not. 93(66.4\%) indicated that they will recommend another person to come to the hospital while 47(33.6\%) indicated that they will not.

Based on the findings on the data presented above, it was concluded that nurses at the university of calabar teaching hospital rendered quality nursing care which was reflected in the positive responses by patients in the hospital.

\subsection{Results for Research Hypotheses}

\section{Hypothesis}

There is no significant influence of knowledge on the practice of quality nursing care among nurses in University of Calabar Teaching Hospital.

This hypothesis is tested using contingency chi-square analysis as presented in table 6 .

Table 6. Contingency chi-square analysis of the influence of knowledge on the practice of quality nursing care among nurses at the University of Calabar Teaching Hospital

\begin{tabular}{|c|c|c|c|c|}
\hline $\begin{array}{l}\text { Knowledge of quality nursing } \\
\text { care. }\end{array}$ & Practice of quality nursing care. & & & $X^{2}$ \\
\hline & Nurses who practiced it & $\begin{array}{l}\text { Nurses who did } \\
\text { not }\end{array}$ & Total & \\
\hline Nurses who have knowledge. & $\begin{array}{c}77 \\
(59)\end{array}$ & $\begin{array}{c}12 \\
(30)\end{array}$ & 89 & 44.1 \\
\hline $\begin{array}{l}\text { Nurses who do not have } \\
\text { tnowle }\end{array}$ & 15 & $\begin{array}{c}36 \\
(18)\end{array}$ & 51 & \\
\hline $\begin{array}{l}\text { Knowleage } \\
\text { Total }\end{array}$ & $\begin{array}{l}(33) \\
92\end{array}$ & $\begin{array}{l}(18) \\
48\end{array}$ & 140 & \\
\hline
\end{tabular}

Result of analysis as presented in table 6 indicates that a calculated $\mathrm{X}^{2}$ value of 44.1 was obtained. This value when compared to the critical $\mathrm{X}^{2}$ value of 3.84 at .05 level of significance and 1 degree of freedom was found to be higher. On the basis of this observation, the null hypothesis was rejected. Meaning that, there is a significant influence of knowledge on the practice of quality nursing care among nurses in University of Calabar Teaching Hospital.

\section{Discussion of Findings}

\subsection{Knowledge of Quality Nursing Care}

The result of findings as presented above revealed that there is a significant influence of knowledge on the practice of quality nursing care among nurses in University of Calabar Teaching Hospital.

This result is supported by Brunner \& Suddart (2008) who reported that a nurse in the clinical setting must be intelligent and be able to make quick decisions based on findings. These decisions are often life saving. She stands to advice other 
team members based on the client's condition skills in critical thinking. This involves application of reasonable question that will help elicit new information to replace old ones. This method of questioning is referred to as Socratic questioning which helps the clinical nurse to reason beyond the physical, especially when the patient's situation is inconsistent.

\subsection{Nurses Practice of Quality Nursing Care to Patients}

The result of findings are also in line with Ihekwaba (2009) who observed that nursing practice is team based, and therefore nursing students and staff nurses are to be equipped with knowledge for proper understanding of the care of their clients. This knowledge is supposed to be applied in care giving by the nurse through proper understanding of rational care and prompt nursing interventions. The clinical environment of the client may change and the nurse will not be required to insist on routine nursing care, but may have to apply critical thinking to device another intervention method based on another theory. Therefore education in theory application is advocated based on knowledge.

The result of findings is again in line with Watson \& Ray (2005) who observed that the growth in the nurses' role and its undefined nature warrants the nurse-clinician to have exposure, using both nursing and medical skills in obtaining baseline data needed for further diagnosis and treatment of client. Nurse patient interaction is however guided by the professional code of conduct.

The result of findings also revealed that nurses at the University of Calabar teaching hospital Practiced Quality nursing care. This result is in line with ANA (2001), who was of the view that the nurse in all professional relationships, practice with compassion and respect for the inherent dignity, worth and uniqueness of every individual, unrestricted by considerations of social or economic status, personal attributes, or the nature of health problems.

The result of findings is also in line with Davis (2003) when he observed that in carrying out nursing care, highly developed technical and interpersonal skills are equally as important as the sensitive observation and intellectual competencies required for the nurse in the nursing situation to arrive at a diagnosis (explanation of a problem at hand) and determination of beneficial nursing actions to be taken. Treatment of a diagnosed condition involves nursing actions that can be described and explained theoretically as to then-relation to phenomena and expected outcome.

\subsection{Patients' Outcome of Quality Nursing Care}

The result of findings further showed that nurses at the University of Calabar teaching hospital Rendered Quality nursing care which was reflected in the positive responses by patients in the hospital. This result is in line with (Sherwood, \& Barnsteiner, 2012), who were of the opinion that nursing actions are intended to produce beneficial effects in relation to identified responses. It is the results of the evaluation of outcomes of nursing actions that suggest whether or not those actions have been effective in improving or resolving the conditions to which they were directed. The results of research study of the relation of particular actions to specific phenomena, determined under controlled conditions, provide more rigorous scientific evidence of beneficial effects to nursing actions than does periodic evaluation or testimonials as to effectiveness.

The result of findings again is in line with Beauchamp \& Childless (2001) who is of the view that the term moral integrity means soundness, reliability, wholeness, and integration of moral character over time. This signifies being faithful to coherent, integrated moral values and actively depending on them when they are threatened. A person of moral integrity is not disordered or disoriented by moral conflict and is faithful to the standards of the common morally as well as to personal moral ideas.

\subsection{Summary of the Study}

The main purpose of this study was to determine knowledge practice and outcome of quality nursing care among nurses in University of Calabar Teaching Hospital (UCTH).

To achieve the aim of this study the following research questions and null hypotheses were formulated to guide this study.

i) What is the level of nurses' knowledge associated with the Quality nursing care render to patient in University of Calabar Teaching Hospital?

ii) What is the level of practice by nurses associated with the quality nursing care render in University of Calabar Teaching Hospital?

iii) What is the outcome of patient associated with the quality nursing care render in University of Calabar Teaching Hospital? 
The hypothesis stated that there is no significant influence of knowledge on the practice of quality nursing care among nurses in University of Calabar Teaching Hospital. Literature related to the variables under study was reviewed according to the research questions and hypothesis formulated to guide the study.

The survey research design was adopted for the study. The design involves the collection of data to accurately and objectively describe existing phenomena, and to make inferences about the population. A total sample of one hundred and forty (140) respondents was randomly selected for the study.

The selection was done through the simple random sampling technique. This was to give each and every members of the population equal and independent opportunity of being selected for the study.

The main instrument used for the collection of data, was the questionnaire. It was administered personally by the researchers with the help of two research assistants.

To answer the research questions and test the hypotheses, frequencies, percentages, and contingency chi square analysis were considered the most appropriate statistical techniques because of the nature of the variables involved in the research questions and the formulated hypothesis directing the study.

The hypothesis was subjected to testing at .05 level of significance with critical values and degree of freedom and the following results were obtained;

i) Nurses at the University of Calabar teaching hospital have knowledge associated with the quality of nursing care rendered to patients at the hospital.

ii) Nurses at the University of Calabar teaching hospital Practiced Quality nursing care.

iii) Nurses at the university of Calabar teaching hospital rendered Quality nursing care which was reflected in the positive responses by patients in the hospital.

iv) There was a significant influence of knowledge on the practice of quality nursing care among nurses in University of Calabar Teaching Hospital.

\subsection{Conclusion}

Based on the result and findings of the study, it was concluded that nurses at the University of Calabar teaching hospital have knowledge associated with the quality of nursing care rendered to patients at the hospital, they Practiced quality nursing care, they rendered quality nursing care which was reflected in the positive responses by patients in the hospital and there was a significant influence of knowledge on the practice of quality nursing care among nurses in University of Calabar Teaching Hospital.

\subsection{Recommendations}

Based on the findings of the study, the following recommendations were made.

That government should employed more nurses as to enhance quality nursing care to patients

The hospital management should always remind nurses of their obligations to patients through continuing education this will help nurses to improve on quality nursing care to patients.

Based on the care patients received it will attract other patients to patronize the hospital.

\section{References}

Abdellah's theory (1960). Emphasize delivering nursing care for the whole person to meet the physical, emotional intellectual, social, and spiritual needs of the client and family. National Open University of Nigeria Press.

Akpabio, A. (2008). Research methods in nursing. ( $3^{\text {rd }}$ ed.).Unical Printing Press.

American Nurses Association (1940). A Tentative Code for the nursing profession. American Journal of Nursing, 26(9), 977-980. ISBN.13:978-1-55810-258-3 www.Nursesbooks.org

American Nurses Association (1968). Code for professional nurses, revised. ANA House of Delegates Proceedings, Vol. 1. New York: ANA. .ISBN.13:978-1-55810-258-3www.Nursesbooks.org

American Nurses Association (2001).Code of ethics for nurses with interpretive statements. Washington, DC: American Nurses Publishing. .ISBN.13:978-1-55810-258-3 www.Nursesbooks.org

Beauchamp, T., \& Childress, J. (2001). Principles of biomedical ethics. $\left(5^{\text {th }}\right.$ ed.). New York: Oxford University Press.www.Nursingworld.org 
Brunner, \& Suddarth (2008). Textbook of medical-surgical nursing. Lippincott $\left(10^{\mathrm{TH}}\right.$ ed.). Philadelphia, USA: Williams and Wolters Kluwer Business.DNLM:1.WY150B89722004 RT41.T462004.

Cronenwett, L., Sherwood, G., Bamsteiner, J., Disch, J., Johnson, J., Mitchell, P., ... (2007). Quality and safety education for nurses. Nursing Outlook, 55(3), 122-131. http://dx.doi.org/10.1016/j.outlook.2007.02.006

Davis, A. J. (2003). International nursing ethics: context and concerns. In Approaches to Ethics, V. Tschudin, $\left(3^{\text {rd }}\right.$ ed.), 95-104. London: Butterworth-Heinemann. http://dx.doi.org/10.1191/0969733003ne587oa

Hamric, A. B. (2000). The nurse as a moral agent in modern care. Nursing Outllook, 47(3), 106. http://dx.doi.org/10.1016/S0029-6554(99)90001-5

Ihekwaba, I. O. (2009). The clinical role of the nurse: A review of challenges to nursing education. International Professional Nursing Journal, 7(2), 26-67.

Lohr, K. N., \& Schroeder, S. A. (1990). A strategy for quality assurance in Medicare. New England Journal of Medicine, 322, 707-712. http://dx.doi.org/10.1891/1061-3749.22.3.461

Rein, M. L., \& Barden, C. (2007). Creating a healthy workplace trust: the foundation for team collaboration and healthy work environment. AACN Advance Critical Care, 18(2), (Apr-June) 103-108.

Sherwood, G., \& Barnsteiner, J. (2012). Quality and safety in nursing. A competency approach to improving outcomes. (eds). Ames, Lowa: Wiley-Blackwell. http://www.wiley.com/WileyCDA/WileyTitle/productCd-EHEP002777.html

Watson. J., \& Ray, M. A. (2005). The ethics of care and ethics of cure: synthesis in chronicity. New York: National League for Nursing.www.watsoncaringscience.org

Williams, K. O. (2004). Ethics and collective bargaining. Calls to action. Online Journal of Issues in Nursing 23 July. www.cno.org

\section{$(\mathrm{cc}) \mathbf{B Y}$}

This work is licensed under a Creative Commons Attribution 3.0 License. 